\title{
LA CONFORMIDAD: HISTORIA FILOSÓFICA Y PARADOJA PROFÉTICA*
}

Dominique de Courcelles**

RESUMEN: Poco a poco, el poder de los Estados y de las organizaciones internacionales se ha hecho más fuerte para castigar la corrupción, el blanqueo de dinero, el financiamiento del terrorismo, y ha suscitado el principio de conformidad como instrumento de protección de las empresas, las compañías financieras y de sus dirigentes, frente a la falta de prevención y de vigilancia. Una historia filosófica de la conformidad permite medir mejor sus paradojas y sus desafios; la conformidad se plantea como una protección apropiada de las sociedades y una condición profética de su desarrollo: respuesta institucional a la inseguridad, instauradora de la moralización de la vida pública.

$$
\text { Sore }
$$

ABSTRACT: The power of Nations and international organizations has gradually become stronger in their fight against corruption, money laundering, and the funding of terrorism. Due to the lack of preventive and inspection measures, conformity has become the means of protecting businesses, financial companies and their leaders. A philosophical account of conformity will help us better understand its paradoxes and challenges. Conformity is presented as a protection mechanism, a framework for development, and an institutional response to the lack of safety, which in turn determines moralization of daily life.

PALABRAS CLAVES: conformidad, prevención, paradoja, protección social, desarrollo. KEYWORDS: conformity, protection, paradox, safety, development.

RECEPCIÓN: 16 de octubre de 2007.

APROBACIÓN: 22 de mayo de 2008.

* Traducción de Mauricio López Noriega.

** Centre National de la Recherche Scientifique, Paris. 
La reproducción total o parcial de este artículo se podrá hacer si el ITAM otorga la autorización previamente por escrito. 


\section{LA CONFORMIDAD: HISTORIA FILOSÓFICA Y PARADOJA PROFÉTICA}

\section{Introducción}

A principios del tercer milenio, la libertad de circulación de capitales y personas facilita la corrupción, el blanqueo de dinero y el financiamiento del terrorismo. Los acontecimientos más decisivos de los últimos años, escándalos financieros o ataques terroristas, han llevado a los Estados y a las organizaciones internacionales a sancionar las fallas de prevención o de control de las sociedades y de sus dirigentes. El poder de sancionar, cada vez más importante, ha suscitado el principio de conformidad como instrumento de protección contra las fallas de prevención o de control. La conformidad a normas, reglamentos u otras especificaciones que permitan paliar dichas fallas puede convertirse en la protección apropiada de las sociedades contemporáneas y, por lo tanto, como exigencia, a la vez respuesta institucional a la inseguridad y condición del desarro1lo, moralización de la vida pública. ¿Pero, hasta qué punto? La emergencia de nuevos poderes y de nuevos enrarecimientos; el trastorno de las representaciones tradicionales de lo político, de lo económico, de lo religioso, todo ello requiere de vigilancia y adaptación. La mayor pregunta es la siguiente: ¿la conformidad, a la cual parece que no se podría escapar hoy, es positiva, protección apropiada y factor de expansión para los individuos y los grupos? ¿Dicha positividad requiere condiciones? 
De inicio, algunos puntos merecen reflexión:

1) ¿A qué se debe estar conformado, si no existe una regla, una norma, una ley? ¿La conformidad resulta de una ley que explica la concepción de lo justo y lo bueno a partir de quien la formula y la aplica?

2) ¿Es posible estar “conforme en sí mismo”? ¿La conformidad en sí no conduce a cierto derivado que lleva otro nombre, el conformismo?

3) ¿Existe una razón de la conformidad que incitaría a pensar que se encuentra ligada al racionalismo económico de los actores económicos?

4) ¿Qué implica la mirada aplicada a la conformidad? ¿Qué significa entonces la denuncia de la no conformidad?

Pero, inclusive: ¿cómo definir las reglas y a quién corresponde hacer1o? ¿Cómo se podría conciliar conformidad con inventiva estratégica, libertad y vigilancia? ¿El riesgo de la no conformidad implicaría un modelo único de dominio? ¿Qué decir sobre la autoregulación? ¿La conformidad impediría que el político se extraviara dentro de los arbitrajes aleatorios, y que el juez se equivocara, debido a que no llegarían a tener el nivel determinado que se requiere técnicamente? ¿En qué medida el dominio de dicho riesgo tomaría en cuenta las especificaciones y las diferencias, tanto aquellas de las empresas como las de los Estados y de los individuos? ¿Cómo se opondría la ley a tales especificaciones y diferencias, como a tantos derechos culturales, y cómo las podría integrar? ¿Existe un costo, no solamente económico, sino también ético y geopolítico de la conformidad? Tantas preguntas, cuya urgencia no es necesario demostrar -como habrá comprendido el lector-, y que no podrán ser resueltas en estas pocas páginas.

Tomemos la voz "conformidad" en Le Robert. ${ }^{1}$ Esta "cualidad de aquello que está conforme” remite a nociones de analogía, concordancia, conveniencia, semejanza, debida proporción, pero también de afinidad, de ver al unísono. "Actuar de conformidad con" supone obediencia, adhesión, sumisión; el vínculo entre conformidad y moral se

${ }^{1}$ Es posible un ejercicio equivalente en castellano: la voz "conformidad", en el diccionario de la $R A E$, apunta a la misma paradoja; por ejemplo: semejanza, igualdad, correspondencia, unión, concordia, frente a adhesión íntima y total, asenso, aprobación, tolerancia. (N. del T.) 
subraya con esta cita de Victor Cousin: "Afirmo que la moral es la conformidad de la acción a la razón. La inmoralidad consiste en desobedecer el juicio de la razón". Y el adjetivo "conforme" se menciona dentro de la frase del Diario de André Gide, de fecha 15 de enero de 1945: "En Francia todo pensamiento no conforme deviene sospechoso y es, en seguida, denunciado". La conformidad, por su amplitud semántica, parece condenada a la paradoja. Intentemos comprenderla.

\section{Grecia y Roma: de la semejanza a la conformidad como virtud de prudencia}

¿Qué es, entonces, la “conformidad”? La noción es muy antigua y aparece en las grandes obras poéticas y filosóficas de la Antigüedad griega y romana. En el núcleo de la palabra conformidad hay forma. ¿Qué es la forma? Forma proviene de la palabra latina forma, que proviene asimis-

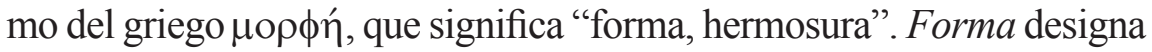
también el molde de la forma del objeto obtenido, sea que se trate de artes y técnicas, de normas o de discursos. Suele traducirse como "idea" en relación con "imagen"; como "forma" en oposición a "materia"; como aspecto, figura, manera de ser, esencia; igualmente como paradigma o modelo, norma, marca, signo distintivo.

En Homero, la "forma" o "apariencia", que es también la "bella forma, la bella apariencia", remite al principio de una conformidad que es la conformidad de afuera y adentro; ${ }^{2}$ aquello que es bello es también bueno. Cicerón hace de la forma el referente inteligible, la idea platónica:

Y en verdad aquel artífice [sc. Fidias], cuando hacía la forma de Júpiter o la de Minerva, no contemplaba a alguien de quien tomara la similitud, sino en la mente de él mismo se asentaba alguna eximia apariencia de belleza [...] A estas formas de las cosas aquel Platón, gravísimo autor y maestro no del entender solamente, sino también del decir, las llama i $\delta \dot{\varepsilon} \alpha \varsigma$, y niega que éstas son engendradas, y afirma que siempre son

${ }^{2}$ Cfr. Il. II, 58 y Od. XVII, 308-454. 
contenidas por la razón y por la inteligencia; que las demás cosas nacen, caen, fluyen, se deslizan...

No obstante, el término forma, ligado a species, aspecto, para Cicerón es también la apariencia que obliga a contentarse con lo probable. Para Séneca, la forma como referente inteligible es asimismo exemplar, tiene la función de modelo, a la vez inteligible y sensible.

Aquello que se contempla en un espejo o en una pintura ha suscitado en la Grecia antigua las primeras reflexiones sobre la cuestión de la forma, de la conformación y de la conformidad. La imagen en el espejo o la pintura es un visible que permite contemplar otro visible. No es ni una cosa ni un concepto, sino una conformación, tal vez producto de la memoria o de la imaginación. Esta imagen encuentra su origen en una imagen mental, que permite validar o no aquello que se mira; dicha imagen, $\varepsilon \imath \delta \omega \lambda o v$, es lo que se contempla como si fuera la cosa misma, cuando no se trata más que de un doble. La imagen de la estatua o del retrato conserva cierta cosa de su modelo, incluso cuando existen distintos grados en esta semejanza. Platón, en el Sofista, al analizar las dos

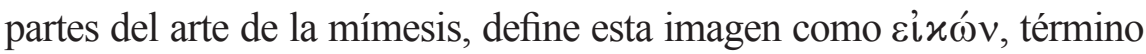
del que proviene ícono, como reproducción fiel que conserva las proporciones y los colores del original, en oposición a $\phi \alpha ́ v \tau \alpha \sigma \mu \alpha$, que es la apariencia falsa. Para Platón, existe una buena $\mu$ í $\mu\rceil \iota \varsigma$, en el sentido de la semejanza, que es el arte de la copia conforme; y una $\mu$ í $\mu \eta \iota \varsigma$, que es el arte de la reproducción, no del ser, sino del aparecer, que distancia de la verdad y hace creer en su verdad. Así, a \&ixóv, imagen y representa-

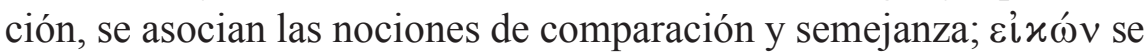

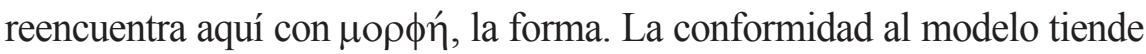
hacia la verdad. El conformismo se vincula a la apariencia, se aleja de la verdad y hace creer en su verdad.

De esta noción de imagen y de semejanza se origina un grupo semántico relativo al mundo moral. La દ̇ $\pi \iota \varepsilon i ́ x \varepsilon \iota \alpha$ es la conformidad, la semejanza, que designa no solamente lo conveniente sino también, en

\footnotetext{
${ }^{3}$ Cic., Orat., II, 98-III, 10. (Versión de Bulmaro Reyes Coria, México, UNAM, 1999. N. del T).
} 
Aristóteles, la equidad, la indulgencia que configura la cualidad de virtuoso del hombre de la ciudad. Dicha equidad es también la virtud del juez capaz de corregir la ley, al ponderar cada caso según aquello que no es la verdad sino lo verosímil, a diferencia de la justicia que guarda la aplicación estricta de la ley. ${ }^{4}$ Así, la conformidad remite a la equidad como virtud de la prudencia, capacidad de invención ética y jurídica, de tensión

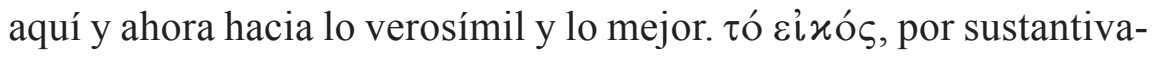
ción del neutro del participio perfecto, es lo que parece verdadero, bueno o normal, lo vero-símil por oposición a lo verdadero y a lo inverosímil. La conformidad está sometida a la ley del comparativo: lo más vero-símil gana sobre lo vero-símil, y tal es el justo resorte de las vueltas entre alegatos de acusación y defensa. La utilidad política que Aristóteles destina a la retórica encuentra aquí su fuente:

Y la retórica es útil por ser, también por naturaleza, más fuertes las cosas verdaderas y las justas que sus contrarias [...] Así pues, es evidente que la retórica no es de absolutamente ningún género determinado, sino así como la dialéctica, y que es útil; y que obra de ella no es el persuadir, sino el hacer ver las cosas persuasivas que existen respecto a cada particular". 5

Si lo verosímil en retórica aristotélica está del lado de lo necesario y de lo general; si es la medida de lo verdadero; si lo verosímil es la medida de lo real, entonces puede considerarse, en la línea de la reflexión aristotélica, que la conformidad se inscribe como medida de lo verdadero y de lo real, sin pretender jamás ser la verdad: la conformidad es lo que permite tender hacia los valores de bondad, justicia y belleza. La acción de imitar y de conformar-se tiene una función de conocimiento, $\mathrm{y}$, por ello, de verdad, en oposición a la acción de fabricar, que corresponde a la ficción, y que implica la mentira y la falsedad. En el Renacimiento, los humanistas como Pico della Mirandola insistirán en la importancia del discernimiento y del juicio, que no deben restringirse a un solo mode-

${ }^{4}$ Cfr. Arist., EN, V, 14.

${ }^{5}$ Arist., Rh, I, 1, 1355a-20-b 10. (Versión de Arturo Ramírez Trejo, México, UNAM, 2002. N. $\operatorname{del} T)$. 
lo, y utilizarán el término inventio para designar la conformidad/conformación de numerosos modelos.

\section{Antígona y el rey: ¿qué conformidad?}

Si para Platón, en Las Leyes, el dios mismo es la medida, para Aristóteles, en la Ética nicomaquea, ${ }^{6}$ es el hombre de bien quien está por sí mismo ordenado; es modelo, principio y medida, justa medida, que sirve para definir la virtud y para inspirar la conformidad a la virtud. Los griegos respetaban las "leyes no escritas" originadas directamente de la divinidad y conformes a lo justo natural, como recuerda la historia de Antígona, leyes que no podían ser apropiadas por ningún tirano. ${ }^{7}$

Cuando Antígona elige enterrar a su hermano para obedecer la ley familiar, "que tiene recompensa a los ojos de los dioses", su hermana le objeta: "Imagina la peor de las muertes si, violentando la ley, transgredimos la sentencia, el poder absoluto de un tirano". ${ }^{8}$ Pero Antígona tiene la convicción de que es a los dioses, y no a los hombres, a quienes ella debe "servir primeramente". La ley a la que ella elige someterse es la divina y no la humana, y el mandamiento del rey no sabrá compa-

34 rársele: "Pues no fue Zeus quien proclamó esta ordenanza, ni tampoco la Justicia, contigua a los dioses infernales. No, entre los hombres no fijaron ellos estas leyes [...] Sin embargo, la tiranía, entre otras muchas felicidades, puede hacer y decir lo que se le antoje", ${ }^{9}$ declara fieramente Antígona a Creonte, rey de Tebas. Al morir, por haber elegido la ley divina y permitir a su hermano entrar en el recinto de los muertos, Antígona misma deviene medida de lo verdadero. "Pues no honras tu autoridad al pisotear la veneración debida a los dioses". ${ }^{10}$ Creonte no supo establecer la diferencia entre las leyes que rigen el universo y las leyes de la ciudad. Las leyes, vó

${ }^{6}$ Pla., Lg., IV, 716c y Arist., EN, V, 11, 1136a 32-33.

${ }^{7}$ Cfr. Ar., $R$, I 1373b 4-12.

${ }^{8}$ S., Ant., 58-60. (Texto Alphonse Dain, 2002, Paris, Les Belles Lettres; traducciones mías, N. del T.).

${ }^{9}$ Ibid., 450-452 y 506-507, respectivamente.

${ }^{10}$ Ibid., 745. 
economía- conforman al viviente, sea humano, animal o vegetal, y la parte humana del viviente puede experimentar enseguida el proceso de inserción dentro de la ciudad. El hombre de bien se conforma a la ley divina, misma que es, en sí, medida de lo justo.

A partir de los griegos, el reino de la ley ha definido, en la cultura occidental, el horizonte normativo de todo orden humano. La "obligatoriedad" es un componente esencial de la normatividad, tanto moral como jurídica. Para Aristóteles, "el orden es ley". ${ }^{11}$ En el pensamiento griego, el discernimiento y el juicio, es decir, la libertad de la interpretación de aquello a lo que se conforma, son salvados por el hecho de que la ley es del orden de la convención; los hombres mismos tienen la capacidad de definir las condiciones normativas de su existencia, y ésta hace destacar su razón y su responsabilidad. La diferencia entre una ley auténtica y un mandamiento arbitrario pasa por la evaluación, que es también discusión, de su contenido normativo. Por haber considerado dicha evaluación como un deber, muere Antígona.

Sensible a la transcendencia de la razón, Cicerón escribió: "La ley no es ni un producto del ingenio humano, ni una decisión arbitraria de los pueblos, sino cierta cosa eterna que reina sobre el mundo entero por la sabiduría de sus mandatos y de sus interdicciones". ${ }^{12}$ Es la conformidad, vista la identidad de la ley con la "recta razón de lo que ella manda y de lo que prohibe", la que crea su legitimidad y la vuelve obligatoria, dice de nuevo Cicerón. ${ }^{13}$ La idea de ley natural, según el Arpinate, remite a un reglamento racional de las prácticas humanas por las normas que no son puras convenciones, sino que proceden necesariamente de una "naturaleza", aquella del mundo o del hombre. Más adelante, el jus naturale del Imperio romano cristianizado considerará las "leyes no escritas" de los griegos como un orden natural garantizado por la divinidad: ley de Zeus esgrimida por Antígona contra Creonte; o, en dicho imperio cristianizado, "derechos naturales" garantizados por la Providencia divina. Agustín estima que la ley humana es justa, pues es ley

\footnotetext{
${ }^{11}$ Arist., Pol., III, XI, 1287a 18-19.

${ }^{12}$ Cic., Leg., II, 8.

${ }^{13}$ Leg., I, 42.
} 
en cuanto se conforma a la ley eterna, que se identifica con el orden de la Creación divina. ${ }^{14}$ Para Tomás de Aquino, los preceptos de la ley natural son accessibles a cada uno: hay, en todo ser humano, una inclinación natural a actuar según la razón”. ${ }^{15}$ El Aquinate hace del "derecho natural" la aproximación "razonable" para los hombres de un derecho divino que sobrepasa su inteligencia. Y John Locke declara que "la ley de naturaleza obliga a todo el mundo". ${ }^{16}$ Estas afirmaciones no asombrarán a aquel que, situado dentro de la tradición de Émile Durkheim, esté convencido de que lo que llamamos razón encuentra su origen en el pensamiento religioso. Así, la noción de conformidad se encuentra ligada a una cierta idea de la trascendencia y de lo universal.

\section{De la justa medida a la recta razón: la escuadra y la norma}

La forma, que designa el molde, designa también el pequeño molde, formula, que dispone las relaciones humanas de forma judicial; proviene, pues, del término griego $\gamma \nu \omega ́ \mu \omega \nu$, que quiere decir "aquello que sirve de regulador o de regla", y remite asimismo a personas conocedoras, expertos, inspectores; por ejemplo, los supervisores de los olivos sagrados, que tenían instrumentos medidores del tiempo y del espacio, como la aguja de cuadrante solar o la escuadra del carpintero. En el derecho clásico de Roma, no se tiene una acción porque se tiene un derecho, pero es posible que se reconozca un derecho, puesto que el pretor ha previsto el pequeño molde de la formula para hacer entrar la pretensión jurídica en causa. A $\gamma \nu \omega ́ \mu \omega v$ está vinculado vó $\mu$ os, que implica a la vez nociones de partición, de ley, de derecho y de obligación. El vónos designa la justicia como expresión primera de la justeza de una medida.

Pasando del griego al latín, de vó $\mu$ os a norma, que es también la escuadra del constructor de ciudades y sin duda tomado del acusativo

${ }^{14}$ De Libero Arbitrio, I, 6, 15.

${ }^{15}$ Summa Theologiae, Prima Secundae, 94, 3.

${ }^{16}$ Second Treatise of Government, II, § 6 . 
de $\gamma \nu \omega ́ \mu \omega \nu$, se llega a las normas de una civilización que se conceden a partir de un derecho, pero también, más generalmente, a partir de lo bueno, lo justo y lo bello, normas que se imponen dentro de la ciudad por un juego de sanciones. Éstas son la crítica, el ridículo, la desaprobación, la segregación e incluso la condena judicial.

Esencialmente humana, la lex de los romanos, para tener toda su fuerza, debía ser grabada y publicada sobre los muros de piedra de las poblaciones; se encuentra en la articulación de la materialidad de los poblados y en la inmaterialidad de la ciudad, confirmando el vínculo entre arquitectura y derecho que significa la norma, escuadra del constructor y norma. Orgullosos de su Ley de las Doce Tablas, redacción de costumbres del siglo $\mathrm{V}$ a. de C., los romanos, y por ejemplo Cicerón, pretendían que nada estaba más cerca de la "recta razón", la razón de la escuadra y la norma, que el derecho romano. Cicerón insiste en el hecho de que, mientras que el vó $\mu$ o $\varsigma$ griego es el hecho de una partición, la lex romana designa una elección deliberada: “Así como los griegos colocan en la ley la idea esencial de la equidad, nosotros colocamos aquella de la elección distinta; tanto la una como la otra son, sin embargo, propias de la ley". ${ }^{17}$ De esta manera, la equidad o la conformidad a aquello que conviene, a lo más vero-símil, reencuentra la elección deliberada o la libertad, que son también lo propio de la "recta razón".

\section{"La razón del más fuerte es siempre la mejor"}

Enseguida de Cicerón y de Tomás de Aquino, el racionalismo jurídico considera que la ley es la obra de la recta razón. Sólo la razón determina el fin al cual debe estar ordenada la voluntad. Sin embargo, para el positivismo jurídico, por ejemplo según Hobbes -en el capítulo XXVI del Leviathan-, la autoridad, no la verdad hace la ley, auctoritas non veritas facit legem. ¿Existe acaso una razón de la fuerza? ¿Puede la razón descansar en la fuerza? Es lo que parecerían sugerir ciertos protagonistas de los Diálogos de Platón; y es conocido el célebre pensamiento de

${ }^{17}$ Cic., Leg., I, 19. 
Pascal: "Al no poder fortalecer la justicia, se ha justificado la fuerza, a fin de que la justicia y la fuerza estuvieran juntos". ${ }^{18}$

En la fábula El lobo y el cordero de La Fontaine, la moral precede al relato, en vez de ser al final: "La razón del más fuerte es siempre la mejor./ Lo hemos mostrado hace poco./ Un cordero bebía..." El lector no puede sino aceptar la afirmación del fabulista; la frase está enunciada como verdadera y siempre verdadera, de validez necesaria y universal. En cuanto al cordero, al calificar inmediatamente al lobo de "Señor" y de "Su Majestad", cimenta él mismo, al comienzo de la fábula, la soberanía del lobo. Si la razón es el poder de discernir lo verdadero de lo falso, la razón del más fuerte es aquella que discierne asimismo lo justo de lo injusto y el bien del mal. El discurso de la fuerza es "moralizado" o autoregulado en términos de justicia: "Me ha sido dicho: es necesario que me vengue". Pero esta equivalencia de discernimiento no es verdadera en sí misma sin un sujeto dotado de fuerza, cualidad que no apunta ni a lo verdadero ni a lo falso, ni al bien ni al mal, sino al cuerpo. ¿La violencia estará siempre en el origen del derecho, la fuerza en el origen de la moral? Es justo lo que parece afirmar el lobo quien, de todas formas, no es culpable, puesto que un misterioso poder -un poder de naturaleza salvaje, un poder de autoregulación, en oposición al de los hombres, al mundo de la cultura y de las convenciones, al que pertenece el cordero domesticado-, le otorga una orden: "Me ha sido dicho: es necesario que me vengue". La venganza consiste precisamente en pretender anular una primera violencia con otra nueva, de tal modo que no hace sino sumarlas. Al comerse al cordero, el lobo afirma que su justicia es aquella de la eficacia económica: comer. El crecimiento, en el sentido corporal, físico, del término, es erigido como juez supremo. Si la razón del más fuerte es siempre la mejor, lo es porque confirma al más fuerte en su prosperidad, en su crecimiento, en su riqueza, en su fuerza, al precio de devorar al otro.

Ya en el medieval Roman d'Alexandre, se encuentra este episodio que corresponde a una fuerte convicción antigua y más grande del pensamiento de la India. El conquistador Alejandro Magno, modelo

${ }^{18}$ Pascal, Pensées, 299, Brunschvicg. 
de toda caballería, llega hasta la India a la desembocadura del Ganges y desciende un día al fondo del mar en un gran navío de vidrio para observar "la vida de los pobladores del océano". ¿Qué nos dice el texto? "Vio a los grandes peces hacer la guerra a los pequeños, / atraparlos y devorarlos [...] sucumbiendo a la fuerza o a la astucia [...] Alejandro observa los grandes y poderosos peces / que engullen a los pequeños, de conformidad con su oficio. / [...] Tal espectáculo hace reír a Alejandro". ${ }^{19}$ El conquistador de la India tiene la firme convicción de que la rectitud, o la justicia, que consiste en estar conforme a su estado -a su karma para retomar el término del hinduismo-implica devorar al otro, más débil, para mantenerse y crecer en su estado. Como en la fábula, "un simple medio económico deviene principio general de conducta", ${ }^{20}$

Conviene mencionar aquí la filosofía moral de John Locke (1632-1704), en la cual la razón ocupa un extenso lugar y la ley moral es anterior a toda apropiación por una conciencia. Para Locke, los valores de bien y de mal están vinculados a la fuerza de la ley, es decir, a la autoridad del legislador. El bien o el mal, identificados con el placer o el dolor sentidos, sólo acceden a la moralidad por su relación con la rectitud, esto es, por comparación con una ley: “Así, moralmente bueno y moralmente malo no son sino la conformidad o la oposición de nuestros actos voluntarios a una ley, que atraen sobre nosotros un bien o un mal debido a la voluntad y poder del legislador". ${ }^{21}$ No existen hechos o términos que lleven en ellos mismos la inmoralidad. La relación efectiva con una ley entraña por sí la moralidad del acto. ${ }^{22}$ Corresponde a cada quien pronunciarse sobre la ley que le "interese" y, en función de dicha ley, evaluar el bien presente de tal acto. La elección o juicio de cada uno es el lugar de la probabilidad, mientras que el conocimiento es el lugar de la certeza. Pero no existe ley que, enunciada por una autoridad, tenga el poder de otorgarle la fuerza. Y Locke subraya que una ley, para obligar, debe tener un poder que le sea conferido no por su racionalidad, en principio, sino por

${ }^{19}$ Le Roman d'Alexandre, 1994, Paris, Le Livre de Poche, Branche III: Voyage sousmarin, p. 321-323.

${ }^{20}$ Max Weber, L'éthique protestante et l'esprit du capitalisme, 1964, Paris, Plon, p. 207.

${ }^{21}$ Essay, 2. 28. 5.

${ }^{22}$ Ibid., 2. 28.16. 
la coacción de una sanción. La elección se cumple, pues, en función del poder de la ley, poder que no es del orden de la persuasión razonable sino del orden de la coacción penal.

Los acontecimientos de la historia reciente han indicado que dicha coacción puede tener cierta eficacia. La fuerza coactiva de la charia o ley islámica y la eficacia actual, financiera y política de la conformidad a la charia, tal como está indicada por el desarrollo de los bancos islámicos, no lo es sin recordar ciertos aspectos del gobierno de Calvino en Ginebra y la eficacia de la conformidad a la ética coercitiva del protestantismo, en particular calvinista y metodista, como lo ha analizado Max Weber. En ambos casos, el bien presente en la acción es esta "bendición" divina, o ese "gobierno apacible", manifestado concretamente en el éxito económico. El "signo" de dicha bendición se obtiene por la acción. Pero Locke recuerda también que lo político o lo religioso que demanda un acto sin juicio exige un acto amoral.

La pregunta, entonces, es la siguiente: ¿cómo se puede creer, razonablemente, en la compatibilidad de la ley religiosa o del determinismo social por un lado, $\mathrm{y}$, por el otro, en la del libre albedrío o elección distinta? ¿Cómo probar que la "conformidad" a tal ley coactiva puede ser positiva, ya que ella sería libremente discernida y elegida, dado que daría lugar al ejercicio del juicio? ¿Acaso la conformidad es positiva puesto que tiene una eficacia económica, puesto que resulta del racionalismo económico, puesto que erige el crecimiento en juez supremo?

\section{"No hay más que locos seguros y determinados": ley natural e incertidumbre normativa}

El siglo XVI fue la época de las guerras civiles, llamadas “de religión”, que asolaron Francia y Europa en nombre de doctrinas religiosas y políticas. El humanista Montaigne, que comprueba en lo cotidiano la violencia asesina de la conformidad a las ideologías, rechaza todo acto admitido sin juicio previo y toda adhesión a una doctrina única. Viajando por Italia, y al encontrarse con un "aristotélico", explica en su Ensayo consagrado 
a "la educación de los niños", es decir, a la educación de su juicio y discernimiento, que dicho "aristotélico" estaba convencido de que "el toque y la regla de toda verdad e idea sólida era su conformidad con la doctrina aristotélica, y que fuera de tal doctrina todo era quimera y vacío; que Aristóteles lo había visto todo y todo lo había dicho". Según este "aristotélico", al tener así un explícito absoluto, nada escapa o puede escapar a Aristóteles; todo es claro y transparente a la luz del "aristotelismo". Pero Montaigne afirma, por su parte, que "no hay más que locos seguros y determinados" ${ }^{23}$ Esta perplejidad reivindicada por Montaigne se debe a la conciencia que tiene de la deriva posible de la conformidad, cuando aparece vinculada a una sola doctrina, que sería la "razón del más fuerte", y se convierte, así, en conformismo. Toda materia, todo saber es bueno para el ejercicio del juicio y, por tanto, de la interpretación. ¿La “doctrina", por su doble carácter de unicidad y obligación, no agotaría la actividad del saber, no vejaría el juicio y la interpretación, no se opondría a fin de cuentas a la vida y a su natural opacidad?

De nuevo, la historia muestra que hay una oposición entre Estados totalitarios, autoritarios o al menos arbitrarios, y un modelo de Estado superior definido por su conformidad al derecho, llamado precisamente Estado de derecho. ¿Pero este derecho es una jerarquía de normas debidamente sancionadas? ¿Un Estado definido por su conformidad al derecho está sometido a normas metajurídicas como los derechos del hombre? La diferenciación de los sistemas normativos es uno de los rasgos constitutivos de la contemporaneidad. Los actores, en tanto sujetos autónomos, deben orientarse en un universo resguardado por normatividades múltiples y frecuentemente contradictorias. En el siglo XVII, un pensador como Grotius aún puede decir: "La ley obliga a aquello que es bueno y loable, y no sólo simplemente a aquello que es justo", ${ }^{24}$ Ahora bien, pertenece a nuestra contemporaneidad, marcada por el pluralismo de las culturas, el manejar situaciones de incertidumbre normativa. ¿Qué es lo que está bien, qué lo que está mal; qué es lo que es bueno, qué lo justo? Esto puede conducir a la tentación de querer restau-

${ }^{23}$ Essais, I, 26, "De l'institution des enfans", 151 B-C.

${ }^{24}$ Droit de la guerre et de la paix, I, 1, 9. 
rar la supremacía de una ley establecida como absoluto, hecha a costa de la ley civil y, por tanto, de las culturas.

Aquí se plantea la cuestión de una "ley natural" que explicaría y justificaría el contenido de ciertas afirmaciones de moral, de política, de derecho. Se va a calificar como elecciones o actos "contra natura", "inhumanos", "perversos" o "moralmente no razonables"; se va a hablar de "violación de los derechos del hombre", de "crímenes contra la humanidad". Los mismos ciudadanos pueden, en ocasiones, invocar una "ley superior" para sustraerse a sus responsabilidades o a sus obligaciones legales, para matar o engañar. En un contexto de pluralismo religioso, ético, económico, donde la "ley natural" pueda ser interpretada de diversas maneras, ¿quién hará de juez en caso de desacuerdo? ¿Es éste el crecimiento? La teoría de la ley natural remite a una teoría general del bien y del mal en la vida humana, que comporta a la vez proposiciones normativas que identifican como buenas o malas, permitidas, obligatorias, etc., ciertos tipos de elecciones y de comportamientos, y de proposiciones no normativas que llevan sobre la objetividad y la racionalidad proposiciones normativas. Los términos "ley" y "natural” son problemáticos dado que se plantean como criterios de valor anteriores a cualquier decisión individual o colectiva, ya que están por encima de todas las leyes, convenciones, prácticas positivas, puesto que son supuestas como objetivas, puesto que aquellos que se adhieren a ellas están convencidos de contribuir a la realización de los individuos y los grupos, y quieren imponer sus convicciones. Existe un rechazo a los escepticismos éticos tradicionalmente formulados contra las normas establecidas por las religiones $\mathrm{y}$, en el contexto nuevo de la globalización de los intercambios comerciales así como financieros, existe también un riesgo de dogmatismo o de convencionalismo moral, ligado a la eficacia económica $\mathrm{y}$, por tanto, reforzado por el imperativo de tal eficacia.

Lo cierto es que se puede mantener la proposición según la cual el conocimiento de lo verdadero es un bien que es necesario buscar -se debe tender siempre hacia lo más verdadero y lo más verosímil-, mientras que la ignorancia, la ilusión y la confusión deben ser evitadas. Tomás de Aquino tiene por primer axioma de moralidad: “es necesario 
hacer y buscar el bien, y negarse a hacer el mal"; por tanto, no se debe actuar gratuitamente, es decir, sin razón, y se debe tener un principio conforme a un bien humano fundamental. En estas condiciones, la distinción entre "ley natural" y "derecho natural" puede ser útil: la ley natural es el conjunto de razones que justifican la afirmación de tal derecho natural, siendo éste la ley natural en su aplicación a determinada clase de personas o a determinado asunto en específico.

Así, el principio de trascendencia de los derechos del hombre es hoy denunciado por algunos como una amenaza para la diversidad cultural y como la manifestación de una voluntad de dominio de Occidente, mientras que es presentado por otros como la legitimación de dicha diversidad. El relativismo cultural deviene muy frecuentemente una justificación ideológica para cometer o tolerar atentados a la dignidad y a las libertades fundamentales de los seres humanos; las especificidades culturales se invocan para justificar prácticas brutales y los ejemplos son, desgraciadamente, numerosos. Cuando Robert Badinter declara: "Yo creo en la universalidad e indivisibilidad de los derechos del hombre, pues siguen siendo el horizonte moral de nuestro tiempo", precisa que es necesario "aceptar que, en su expresión, los derechos del hombre revisten aspectos culturales diversos". ${ }^{25}$ La universalidad de los derechos del hombre no está en contradicción con la diversidad cultural; el derecho a la diferencia es un derecho del hombre; no es que sea necesario, dado que la noción de humanidad apareció de forma tardía, renunciar a hacer surgir la voluntad de reconocer los derechos comunes a todos los seres humanos en los diversos puntos del mundo. La determinación jurídica positiva, preocupada por articular lo universal y lo particular, sin que nada sea jamás paralizado definitivamente, fijado, parece ser entonces complementaria a la exigencia moral. Desde esta perspectiva, sin duda conviene reflexionar sobre el riesgo de caer en un dogmatismo o convencionalismo moral de la conformidad, evocado más arriba, vinculado con el imperativo de la eficacia económica.

En línea con la reflexión de Majid Rahnema, que se interroga sobre la causa del "crecimiento del número de hombres y mujeres acosados

${ }^{25}$ Entrevista con Robert Badinter, Presidente de la Misión para el Cincuentenario de la Declaración Universal de los Derechos del Hombre, Le Monde, 18 septiembre de 1998. 
por la miseria, justo mientras no cesan de multiplicarse los grandes proyectos de ayuda a los pobres y cuando la economía dispone de todos los medios necesarios para, al menos, asegurar su supervivencia", ${ }^{26}$ conviene interrogarse sobre la conformidad, en tanto objeto y preocupación jurídica de "moralización" de la vida de las empresas y de los intercambios, por la articulación de lo universal y lo particular, justo cuando el aumento de la concurrencia parece permitir, si no imponer, todos los rumbos.

\section{La empresa: "nuevo territorio" de lo humano}

Hoy, una de nuestras convicciones y reivindicaciones más importantes a propósito de nosotros mismos es que somos agentes moralmente responsables. Esta responsabilidad moral encuentra fundamento en el libre albedrío y, a fin de cuentas, en nuestro autocontrol, el cual incluiría, a la vez, la existencia de otras opciones posibles y la capacidad de discernimiento y de elección, de tal forma que conozcamos - o consideremos conocer- nuestras propias determinaciones.

Hoy, es la empresa transnacional, transcultural, que se establece como sociedad, la que aparece como el "nuevo territorio" de lo humano. En función de lo que quiere, en función de su cultura, la empresa necesita normas o reglas específicas y coherentes. Se admite, generalmente, que puede ser el vector eficaz de las respuestas a las grandes amenazas contemporáneas y que sus políticas de desarrollo sostenible podrían constituir el vector de los derechos del hombre. A ella corresponde el imperativo kantiano de "siempre tratar al ser humano como un fin y jamás como un simple medio", que sigue siendo uno de los principios supremos de moralidad, pues es un principio conforme a un bien humano fundamental que está especificado en las normas morales que condenan la muerte o el fraude o la corrupción. Este principio encuentra su expresión en los derechos del hombre, que no son solamente inalienables, sino también inviolables. Sud, p. 11.

${ }^{26}$ Majid Rahnema, Quand la misère chasse la pauvreté, 2003, Paris, Fayard/Actes 
Debido a que la empresa, fuera de territorio nacional, se enfrenta a problemas de legislación, de legitimidad y de legitimación, su responsabilidad social consiste, entre otras cosas, en suscitar "códigos de conducta" o "códigos de ética" destinados a paliar la insuficiencia de la ley, que contiene lagunas, injusta ciertamente. Así, surgen nuevas autoridades de regulación, economizando la justicia y también la política. Lo que sería la "ley natural", general e impersonal, se encuentra necesariamente enmendada por reglamentos internos que supuestamente permitirían la responsabilización y serían portadores de valores específicos. Es posible sostener que existen diferentes opiniones posibles, diferentes códigos de conducta o códigos de ética, frente a una elección que tiene una inclinación moral significativa, que remite a diferentes manifestaciones de un solo y mismo bien.

Para Kant, una ley concebida como un medio para la felicidad o para el bien común - una administración equilibrada o una buena gobernabilidad, la eficacia económica admitida como bien común-induce necesariamenta a una heteronomía de la voluntad, puesto que aquí se encuentra determinada en su acto hacia un fin o un objeto que ella misma no produce. Un precepto tal no merece el nombre de ley; es, cuando más, una "regla de habilidad" o un "consejo de la prudencia". La idea de ley, en cambio, corresponde a aquella del imperativo categórico; es un mandamiento incondicional al cual se obedece por deber, por respeto a la ley misma. Pero una aproximación semejante no toma en cuenta el enraizamiento de toda ley en una red de hechos y de significaciones históricas, políticas y culturales; la condición de efectividad de las leyes, ha mostrado Hegel, es que rigen y reconocen la expresión objetiva y racional de su propio ethos que remite a su cultura, en el sentido amplio del término: civilización. Este reconocimiento pasa por el diálogo y la elaboración común. La evaluación del contenido normativo por cada uno es un trabajo incesante en su renovación, perfectible. La conformidad no podría estar vinculada a una "doctrina" única, a un "pensamiento único" y fijo. Por otro lado, el imperativo de la eficacia económica y de la fluidez no podría ser sustituido por imperativos religiosos tradicionales y sustituir un dogmatismo por otro, ni tampoco podría sustituir los principios conformes a 
los bienes fundamentales, mismos que han podido ser enunciados por pensadores tan diferentes entre sí como Tomás de Aquino o Kant.

Los códigos de conducta o de ética de las empresas, que producen el objeto de esta nueva disciplina de las empresas, que es la "conformidad", estarían así más del lado de las "reglas de habilidad" y de los "consejos de la prudencia" que del lado de la ley; jamás podrían ser mandamientos incondicionales, incluso si tienen la misma condición de efectividad que las leyes, a saber, la necesidad de un reconocimiento propio por aquellos que rigen en los diversos puntos del mundo. No pueden ser móviles de la acción, sino sus marcos. Y es bien sabido que no existe sociedad humana viable si los hombres se rehúsan a garantizar aquello que es la base del tejido social, es decir, la posibilidad del intercambio recíproco, la estabilidad de los compromisos, de las promesas y los contratos, la eficacia de la amenaza y de la disuasión.

\section{La confianza y el porvenir}

En estas condiciones, sin duda la "conformidad" puede devolver a la confianza toda su importancia y toda su performatividad, si es dicha virtud de equidad y prudencia capaz de ponderar la ley general, con lagunas, injusta ciertamente; si es esta tensión hacia lo verdadero, lo bueno, lo bello, capaz de economizar la justicia y la política; si está vinculada a la "recta razón", articulando lo universal y lo particular; si se guarda del estricto racionalismo económico, así como del estricto convencionalismo moral, y subraya la responsabilidad y movilidad de los diferentes actores de la empresa y la necesidad de un perpetuo reajuste y renovación de los principios. En estos tiempos de "crisis", confianza es una palabra que no se deja de escuchar en los discursos de los economistas, políticos y, de igual forma, en los de los moralistas. Es, exactamente, lo que eligiera Montaigne y también de lo que dan testimonio sus Ensayos: tomar en cuenta la complejidad y la fluidez de lo real, aceptar el no-dominio de lo real y tener confianza en el hombre y en sí mismo. Si implica la constante participación de seres autónomos y racionales en las implicaciones necesarias de la equidad, su acuerdo sobre un conjun- 
to de principios de justicia particulares, cuidadosamente formulados y jerarquizados, entonces la conformidad restaura la confianza entre ellos y puede ser la estructura de base de la empresa y, por lo mismo, de la sociedad. La conformidad otorga realidad al porvenir.

La conformidad, en tanto acuerdo sobre un conjunto de principios de justicia particulares, que permite la confianza no solamente al interior de una empresa sino igualmente de manera transnacional, transcultural, inscribe las insuficiencias de prevención o de control en el porvenir y permite decir que el porvenir es ya, en cierto modo, lo que será. La corrupción, el blanqueo de dinero, el financiamiento del terrorismo, todos los escándalos, pero también los rumbos de un crecimiento erigido como juez supremo y la alienación de la libertad a las inclinaciones y a los intereses propios, todos esos hechos, antes de que sucedan de manera ineluctable, pueden dejar de producirse. En este intervalo se desliza la libertad del acuerdo sobre un conjunto de principios particulares de justicia y en el que la ética puede afrontar la racionalidad instrumental, al considerar que los intereses que ponen en conflicto las partes los incitan, asimismo, a la cooperación. La conformidad remite así a la actividad de predicción de los profetas de la Biblia, que no predecían solamente para hacer conocer el porvenir, sino también para actuar sobre el mundo. Tal es el caso del profeta Jonás, quien, al profetizar la caída de Nínive a sus habitantes, provoca su arrepentimiento y, por tanto, su salud al conformarlos a la voluntad divina. Pero Jonás habría querido no profetizar a los habitantes de Nínive, que eran los enemigos tradicionales de Israel; su palabra profética, conforme a la voluntad divina, produce un resultado que él mismo, alienado por sus propias inclinaciones e intereses, no habría podido desear. La sanción, en caso de no aplicación de la conformidad, en último término puede tener resultados que rebasan aquellos que ha formulado la conformidad o aquellos que ha denunciado su no aplicación en tal circunstancia precisa. Y la necesidad de la conformidad, por último, se abole. El filósofo Hans Jonas escribió: "La profecía de la desgracia existe para evitar que se realice". ${ }^{27}$

${ }^{27}$ Hans Jonas, Le Principe Responsabilité. Une éthique pour la civilisation technologique, 1995, Paris, Flammarion, p. 233. 
La reproducción total o parcial de este artículo se podrá hacer si el ITAM otorga la autorización previamente por escrito. 